\title{
Ultrasound demonstration of a benign gastric ulcer with gastric outlet obstruction
}

\author{
PL PATteE MD, HH TAO MD, R BHARGAVA MD, A AL-AlWADHI MD
}

PL PATteE, HH TAO, R BHARgaVA, A AL-AlWADHI. Ultrasound demonstration of a benign gastric ulcer with gastric outlet obstruction. Can J Gastroenterol 1994:8(1):41-44. A benign antral gastric ulcer in an adult causing gastric outlet obstruction was demonstrated by ultrasonography. The extent and benign nature of the ulcer was suggested by ultrasound before gastric surgery was performed. Features implying a benign gastric ulcer were: observation of peristaltic waves through the underlying muscular layer, homogenicity of the ulcer crater and characteristic mound or volcano-like appearance of the heaped-up folds of mucosa. The differential diagnosis and the role of ultrasound in the diagnosis of gastric ulcers are discussed.

Key Words: Gastric outlet obstruction, Peptic ulcer, Ultrasound

\section{Échographie de l'ulcère gastrique bénin avec obstruction pylorique}

RÉSUMÉ : Un ulcère gastrique antral bénin chez un adulte, provoquant une obstruction pylorique, a été révélé à l'échographie. L'étendue et la nature bénigne de l'ulcère ont été suggérées par l'échographie avant la chirurgie gastrique. Les caractéristiques indicatrices d'un ulcère gastrique bénin étaient : la présence d'ondes péristaltiques dans la couche musculaire sous-jacente, l'homogénéité du cratère ulcéreux et l'aspect caractéristique en forme de volcan des plis rapprochés de la muqueuse. Le diagnostic différentiel et le rôle de l'échographie dans le diagnostic des ulcères gastriques sont présentés ici.

\footnotetext{
$\mathrm{C}$
} URRENT PRACTICE DICTATES that gastric ulcers are diagnosed by endoscopy, biopsy and contrast radiography. To date, ultrasound in adults has contributed little to the diagnosis of this entity. Benign gastric ul- cers have been associated with gastric wall thickening (with or without ulcer crater) and loss of the five-layer structure of the gastric wall $(1,2)$. However, these are not only features of benign ulceration, but also are observed in ul-

Gastroenterology, Diagnostic Radiology and Rheumatology Departments, University of Ottawa; Department of Radiology, Ottawa Civic Hospital, Ottawa, Ontario

Correspondence: Dr PL Pattee, 40 Anna Avenue, Ottawa, Ontario K1Z 7T4. Telephone

(613) 725-0470

Received for publication May 4, 1993. Accepted June 7, 1993

cerative carcinoma, lymphoma, metastases, submucosal tumours and gastritis $(2,3)$. By ultrasound criteria alone, prediction of gastric lesion histology is difficult.

We report the ultrasound demonstration of a benign antral ulcer causing gastric outlet obstruction. Several features of this case allow not only the demonstration of a gastric ulcer by ultrasound, but also - possibly - prediction of ulcer benignity.

\section{CASE PRESENTATION}

A 72-year-old man with Alzheimer's dementia was admitted to hospital twice in the period between October 1989 and February 1990 with upper gastrointestinal bleeding. Endoscopy on both occasions revealed a large antral ulcer. Repeated biopsies of the ulcer showed no malignancy. The patient was treated medically with blood transfusions and ranitidine.

The patient was readmitted in March 1990 with symptoms of gastric outlet obstruction. Abdominal ultrasound using 3.5 and/or $5 \mathrm{mHz}$ transducers revealed an antral hypoechoic area of symmetrical, homogeneous, heaped-up mucosa in the shape of a volcano (Figures 1-3). The opening of the volcano-shaped area was filled with hyperechoic substance, presumably blood clots or debris. A peristaltic wave was demonstrated through the muscu- 


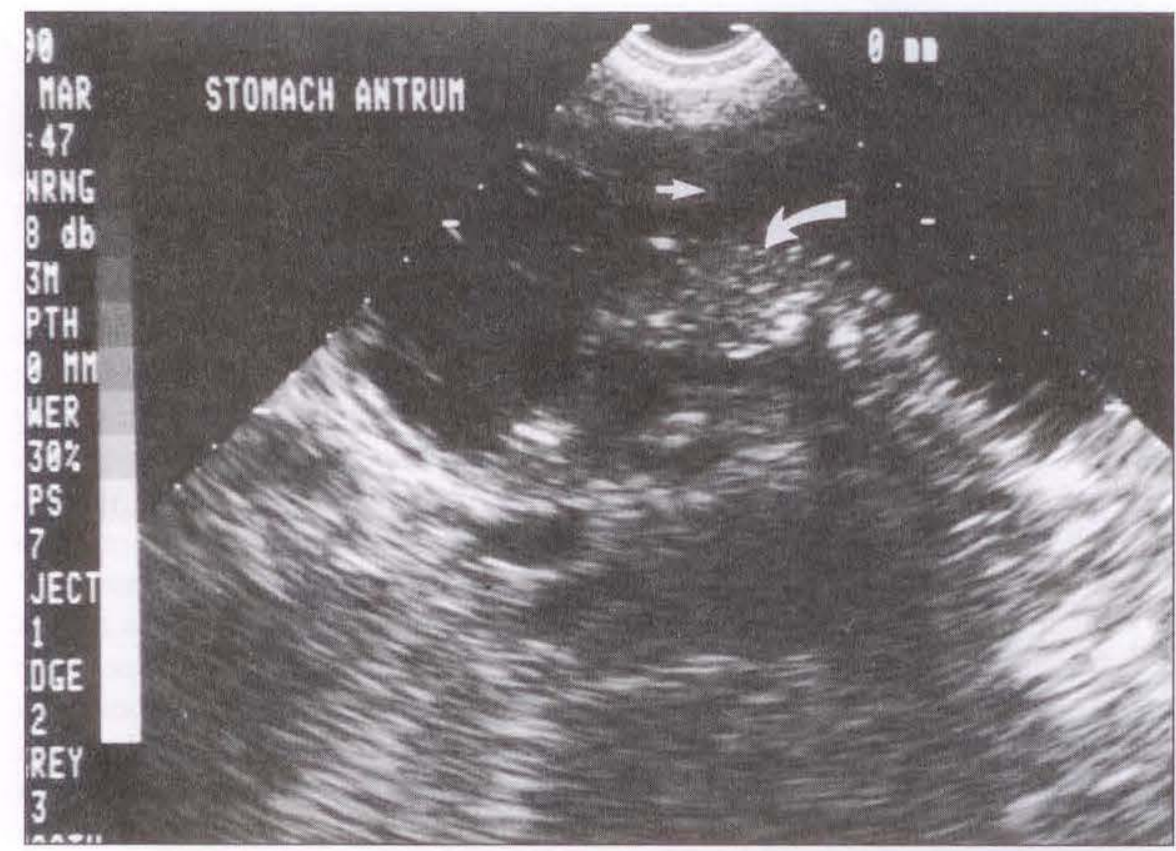

Figure 1) Sonogram of gastric antrum showing a symmetrical, homogeneous area of heaped-up, mucosa in the shape of a volcano

laris layer (Figures 2,3). An upper gastrointestinal series showed thickened folds in the antral region leading into a deep ulcer crater (Figure 4). Despite multiple attempts at positioning, the ulcer could not be demonstrated on profile during the barium examination.

The patient then underwent a subtotal gastrectomy with Billroth II gastrojejunostomy $24 \mathrm{~h}$ later. The surgical specimen showed a perforated benign antral ulcer and chronic gastritis with intestinal metaplasia (Figures 5,6).

\section{DISCUSSION}

The classical roentgenological demonstration of a gastric ulcer on profile view is a conical or volcano-shaped projection form the gastric lumen. Signs of a benign gastric ulcer are clear projection of the ulcer outside of the lumen, the Hampton line, an ulcer collar and a symmetrical ulcer mound (4). These findings can also be applied to sonography.

There have been several reports concerning the role of transabdominal ultrasound in the diagnosis of peptic ulcer disease in adults (1-3,5-10). All observed wall abnormalities are features of peptic ulcer disease. Sonographic wall abnormalities included increased wall thickness, asymmetric mucosal thickening, loss of the ability to distinguish between gastric wall layers, and spasm and deformity of the muscularis. In only one of the studies were gastric ulcers directly visualized (2). This report is the second in the English literature demonstrating direct sonographic visualization of a gastric ulcer.

The surgical specimen showed that the ulcer had actually perforated by the time of surgery. This had not been demonstrated by the preoperative imaging, possibly indicating that the perforation was small or occurred in the immediate preoperative period. Demonstration by ultrasound of gastric ulcer perforation has been reported $(2,5)$. Findings indicating perforation are pneumoperitoneum, various fluid collections (subphrenic, subhepatic, gallbladder fossa) and demonstration of a sinus tract $(2,5)$.

We suggest that our case demonstrates previously undescribed sonographic features that imply a gastric ulcer may be benign: homogeneous echogenicity of the ulcer crater, the characteristic mound or volcano-like appearance and, particularly, observation of peristaltic waves through the

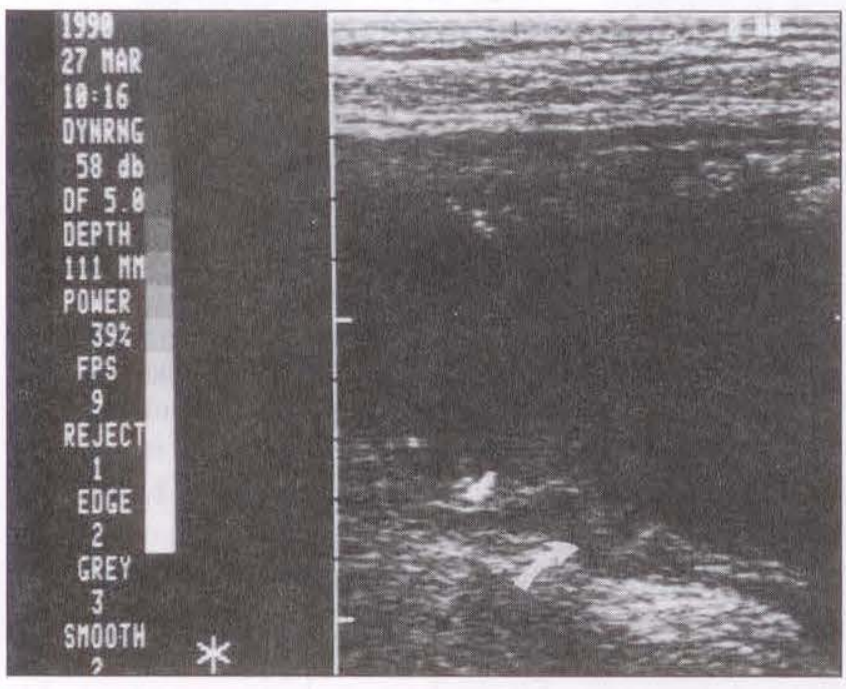

Figure 2) Sonogram showing evidence of a peristaltic wave seen in the muscularis propria layer and continued in Figure 3

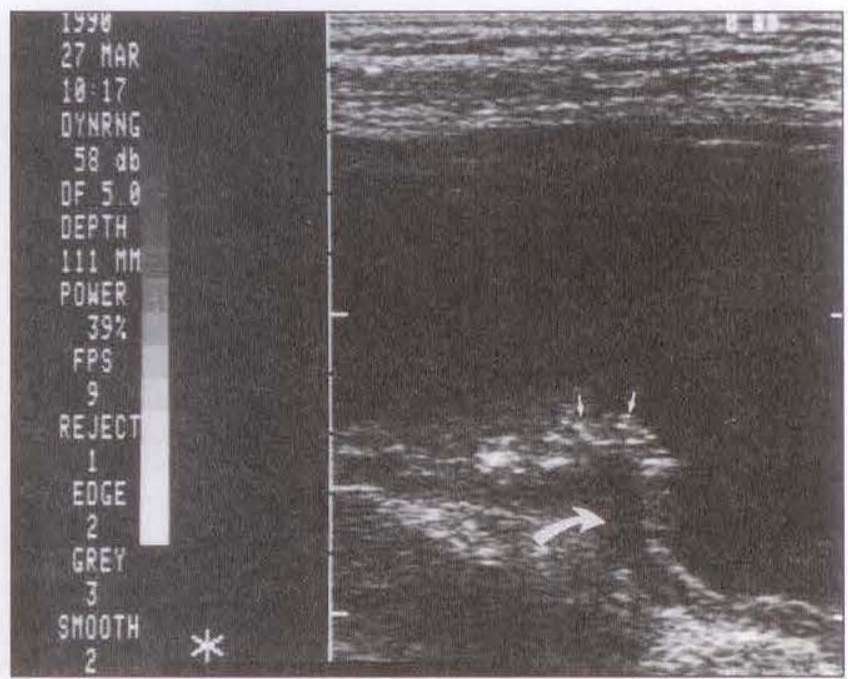

Figure 3) Scan obtained 1 min after scan in Figure 2 shows further propagation of the peristaltic wave. Also, hyperechoic material is seen in the opening of the volcano-shaped area, presumably representing blood clot or debris 
ulcer region on real-time scanning. The former are similar to classic roentgenographical criteria for gastric ulcer benignity. In comparison, features suggestive of carcinoma include: gastric wall thickening, localized or diffuse and smooth or irregular; a globular mass, nodular or irregular, poorly or irregularly echogenic or containing a necrotic cavity; and a combination of both (3). Uniform gastric wall thickening and loss of the ability to distinguish between gastric wall layers have previously been described as a sign of both benign and malignant gastric ulceration (2).

There are inherent difficulties in imaging the stomach because of frequent presence of gas or food debris, anatomi$\mathrm{cal}$ position (leading to areas of the stomach being inaccessible to ultrasound), spasm and obesity. Gastric outlet obstruction allows accumulated fluid in the stomach to provide a sonographic window to examine the layers of the posterior stomach wall. Detection of a large amount of fluid in the stomach on sonography also appears to be a feature of duodenal ulcer disease and gastric hypersecretory states (6). Graded compression was found to be useful for visualizing the posterior wall of the stomach. Cases in the literature, as in our case, always involved large ulcers in the antrum, thus allowing successful demonstration by ultrasound.

Ultrasound would have been useful in the follow-up of this patient had surgery not been performed. In patients where endoscopy is not appropriate,

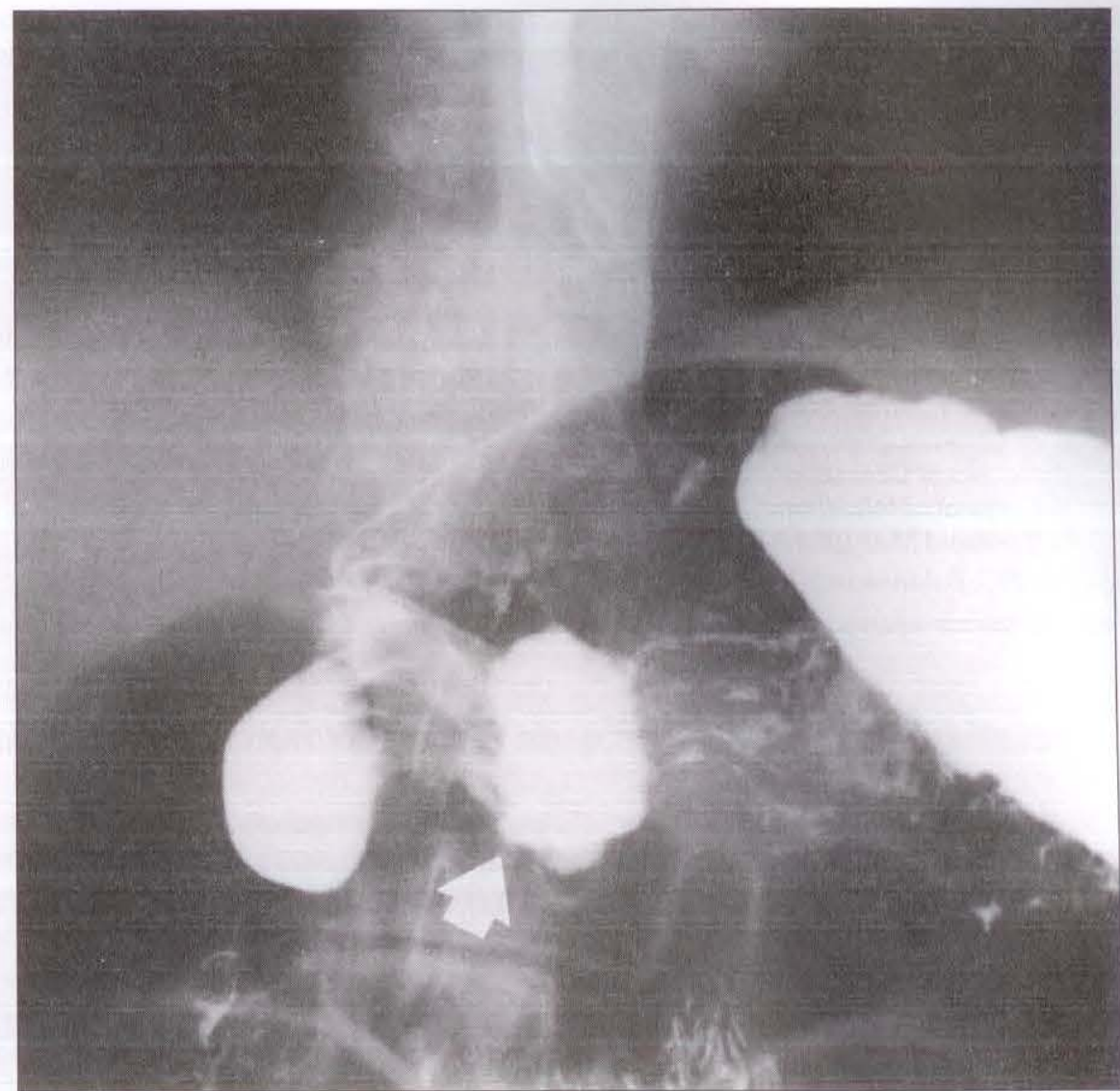

Figure 4) Selected film from the upper gastrointestinal series showing thickened folds in the antral region leading into a deep ulcer crater

sonography may be suitable for diagnosis and for monitoring the healing process. We do not suggest that ultrasound replace endoscopy or barium imaging, but instead be used as an adjunctive diagnostic method. With use of a fluidaided technique (1), ultrasound could be used in a wider group of patients; however, it may impede further investi- gations by endoscopy or upper gastrointestinal series.

\section{CONCLUSIONS}

The authors report features on ultrasound that suggest a gastric ulcer may be benign: homogenicity of the ulcer crater; characteristic mound or volcano-like appearance of the heaped-up

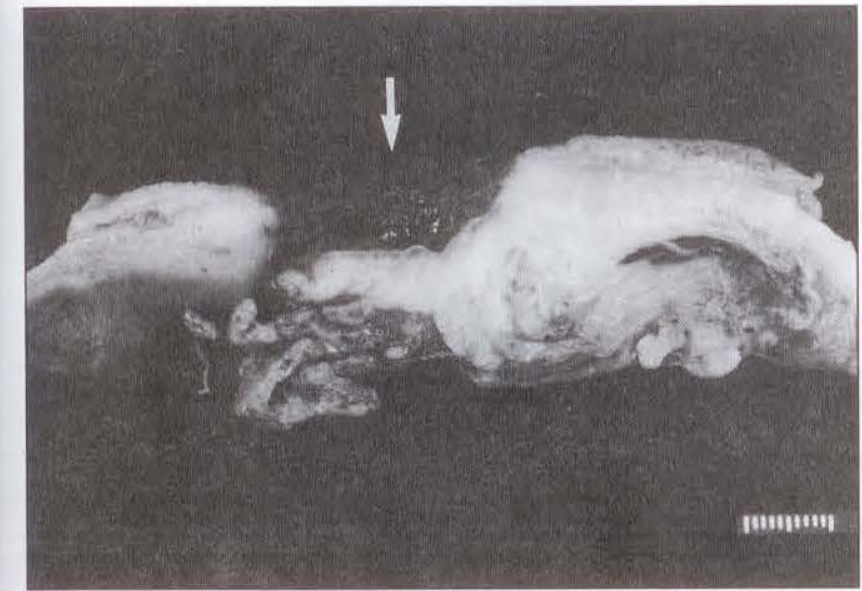

Figure 5) Photograph of surgical specimen showing antral ulcer in profile

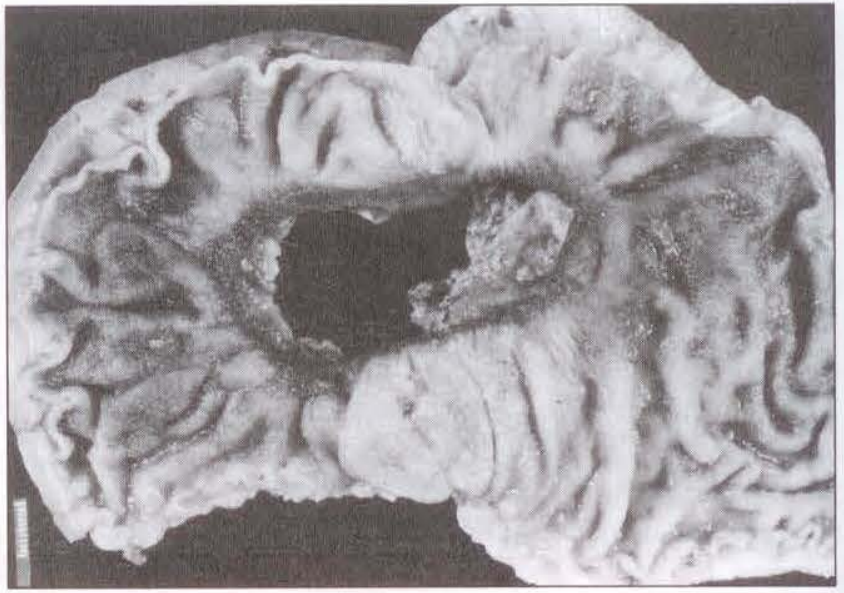

Figure 6) Photograph of surgical specimen showing antral ulcer en face 
folds of mucosa; and, particularly, observation of peristaltic waves through the underlying muscular layer.

\section{REFERENCES}

1. Joharjy IA, Mustafa MA, Zaidi AJ. Fluid-aided sonography of the stomach and duodenum in the diagnosis of peptic ulcer disease in adult patients. J Ultrasound Med 1990;9:77-84.

2. Tomooka Y, Onitsuka H, Goya T, et al. Ultrasonography of benign gastric ulcers: Characteristic features and sequential follow-ups.

J Ultrasound Med 1989;8:513-7.

3. Yeh HC, Rabinowitz JG.
Ultrasonography and computed tomography of gastric wall lesions. Radiology 1981;141:147-55.

4. Eisenberg RL. Gastrointestinal Radiology: A Pattern Approach. New York: Lippincott Company, 1983:179-90.

5. Madrazo BL, Hricak H, Sandler MA, et al. Sonographic findings in complicated peptic ulcer. Radiology 1981;140:457-61.

6. Smithuis RHM, den Oyth JOO. Gastric fluid detected by sonography in fasting patients: Relation to duodenal ulcer disease and gastric-outlet obstruction. Am J Radiol 1989;153:731-3.
7. Rosenberg ER, Morgan CL, Trought WS, et al. The ultrasonic recognition of a gastric ulcer. $\mathrm{Br} J$ Radiol 1980;53:1014-6.

8. Nyberg DA, Laing FC.

Ultrasonographic findings in peptic ulcer disease and pancreatitis that simulate primary gallbladder disease. J Ultrasound Med 1983;2:303.

9. Lutz HT, Petzoldt R. Ultrasonic patterns of space occupying lesions of the stomach and intestine. Ultrasound Med Biol 1976;2:129.

10. Bluth EI, Merritt CRB, Sullivan MA. Ultrasonic evaluation of the stomach, small bowel, and colon. Radiology 1979;133:677 


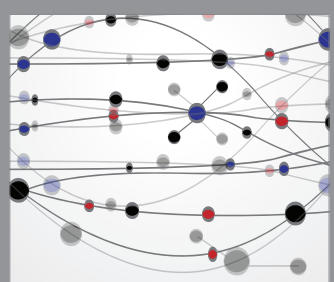

The Scientific World Journal
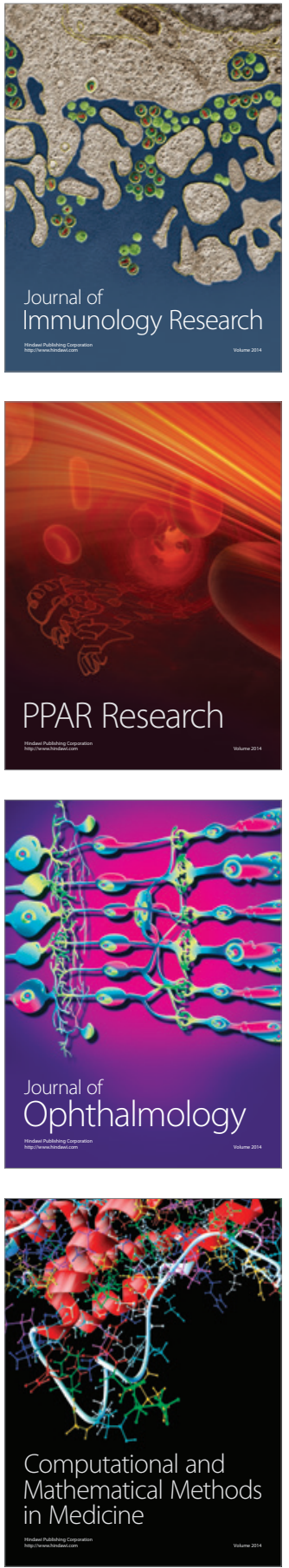

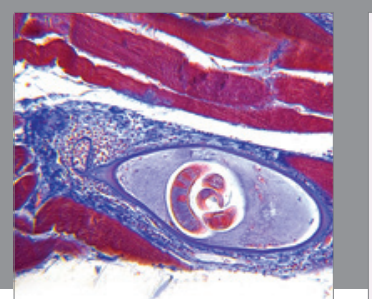

Gastroenterology Research and Practice

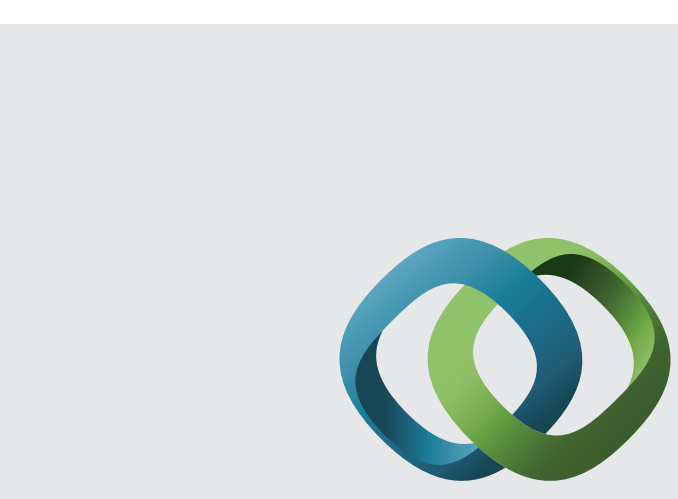

\section{Hindawi}

Submit your manuscripts at

http://www.hindawi.com
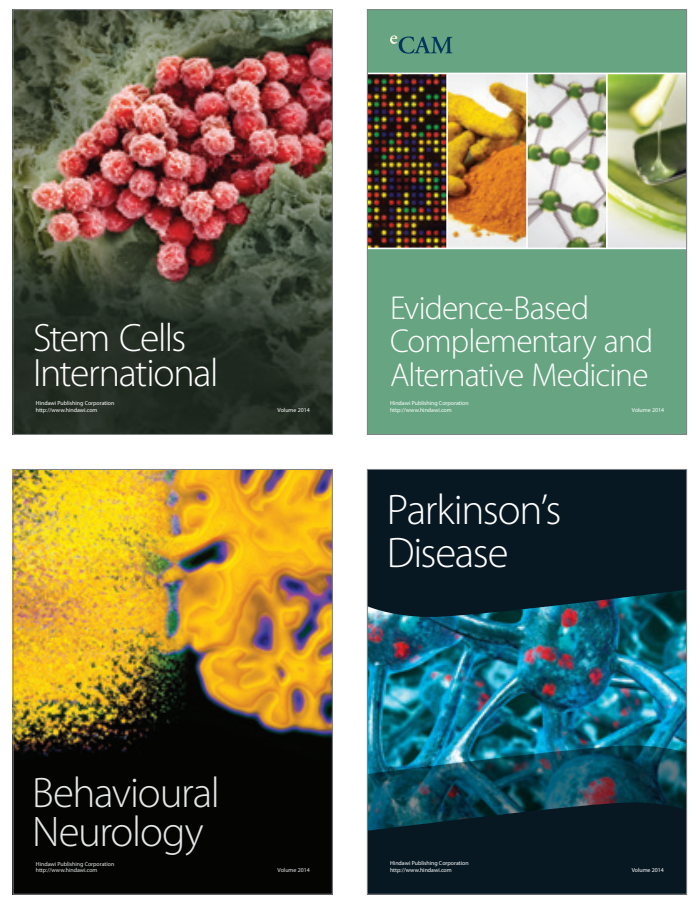
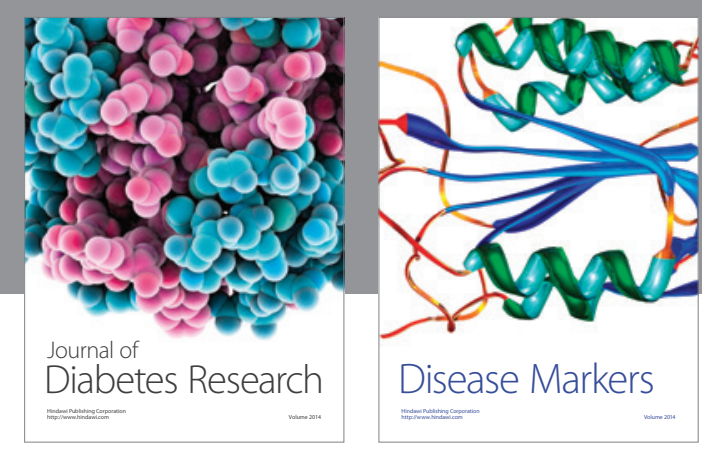

Disease Markers
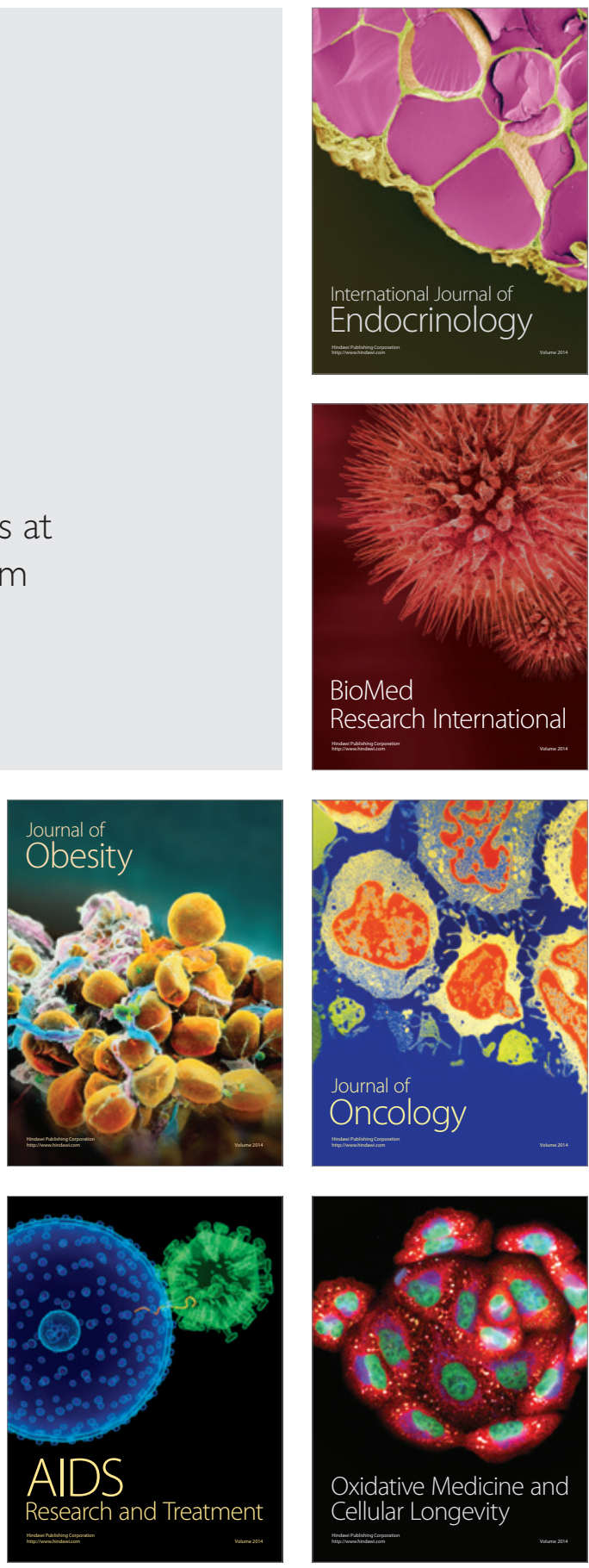